\title{
Effect of Certain Immunosuppressants on Non-specific Immunity Cells in Murine Corneal Grafts: Study on Early Phases after Transplantation
}

\author{
P. BYSTERSKÁ ${ }^{1}$, P. SVOZÍLKOVÁ ${ }^{1,2}$, H. FARGHALI \\ ${ }^{1}$ Institute of Pharmacology, ${ }^{2}$ Department of Ophthalmology, First Faculty of Medicine, Charles \\ University, Prague, Czech Republic
}

Received August 4, 2006

Accepted September 7, 2006

On-line available December 19, 2006

\begin{abstract}
Summary
The aim of our study was to evaluate the efficacy of FK506, mycophenolate mofetil (MM) and aminoguanidine (AMG) on infiltration of macrophages (MPHs), neutrophils (NPHs) and dendritic cells (DC) into corneal grafts during the early phases after transplantation (Tx). Tx was performed in mice (C57BL/10 to BALB/c). Therapy included FK506 $(0.2 \mathrm{mg} / \mathrm{kg}), \mathrm{MM}(30 \mathrm{mg} / \mathrm{kg})$ or AMG $(0.1 \mathrm{~g} / \mathrm{kg})$, started at the day of Tx and was injected i.p. daily. Corneas were excised on the 3rd and 7th day after Tx. Immunohistological evaluation using antibodies against MPHs, NPHs and DC was performed and corneal grafts were assessed in the periphery and in central part of the cornea separately. On the 3rd day after Tx, a massive infiltration of MPHs and NPHs into corneal grafts was revealed; the DC infiltration was lower in all treated groups. Treatment with FK506 and MM led to a significant reduction of NPHs in the centers of the grafts, but not of MPHs. In contrast, AMG significantly reduced MPHs migration into allografts on the third day after Tx, whereas NPHs infiltration has not been attenuated. However, immunosuppressants had no influence on the infiltration of DC during early phases after Tx.
\end{abstract}

\section{Key words}

Corneal transplantation $\bullet$ Immunosuppressants $\bullet$ Macrophages $\bullet$ Neutrophils $\bullet$ Dendritic cells

\section{Introduction}

Corneal transplantation $(\mathrm{Tx})$ is the most common form of tissue allotransplantation, far exceeding all other cases of solid tissue Tx (Dana et al. 2000). In uncomplicated cases (non-vascularized, low-risk recipients), the five-year graft survival rate is over $90 \%$, while in inflamed and vascularized corneal graft recipients, success rates may be as low as $20 \%$. This extraordinary rate of success, has been related to various features of the cornea and ocular microenvironment that together account for its immune-privileged status (Qian et al. 2001, Hargrave et al. 2003). However, the incidence of rejected allografts in long-term follow up studies is 
surprisingly high in both humans and rodents, suggesting that the privileged status of the cornea is not absolute (Plšková et al. 2004). Although thousands of transplants are performed annually, many of these fail because of immunological rejection, which is the most common cause of corneal graft failure (Hargrave et al. 2003, Hegde et al. 2005). Clinically and experimentally, rejection of corneal grafts is recognized as opacification of the cornea. It is thought that various components can contribute to opacification or to reduced clarity of the cornea including cellular infiltration, new vessel ingrowth, thickening and irregularity of the cornea, and edema (Plšková et al. 2002).

Corneal allograft rejection is histologically characterized by massive infiltration of CD4+ T-cells and macrophages (MPHs). Significant numbers of neutrophils (NPHs) and NK cells were also found in the cellular infiltrates. Recent studies have shown that dendritic cells (DC) form a part of the cellular infiltration of rejected human corneal grafts (Hegde et al. 2005, Torres et al. 1996, Kuffová et al. 2001, Bradley 2002).

$\mathrm{CD} 11 \mathrm{c}+\mathrm{CD} 11 \mathrm{~b}+$ myeloid $\mathrm{DC}$ are present through the anterior stroma. Inflammatory stimuli determine the maturation stage of DC and their tolerogenic and immunogenic properties in the immune system. It is known that an increasing number of $\mathrm{MHC}$ class II-bearing DC in cervical draining lymph nodes correlates directly with the retinal tissue damage. This implies that DC at different maturation stages might be the main initiators of this devastating tissue destruction (Hamrah et al. 2003a, Novak et al. 2003, Yamagami et al. 2003, Maruyama et al. 2005).

In some cases, immunosuppressive drugs are not able to prevent rejection. The triggered mechanism is unknown, but it has been described that MPHs, NPHs, DC, activated T-cells and B-cells take part in the rejection process (Larkin et al. 1997b, Bradley 2002).

The aim of this study was to delineate the infiltration of non-specific immunity cells (MPHs, NPHs, DC) into corneal allograft on the third and seventh day after Tx and evaluate the effect of selective calcineurin inhibitor FK506, reversible uncompetitive inhibitor of inosine monophosphate dehydrogenase mycophenolate mofetil (MM) and specific inhibitor of inducible nitric oxide synthase aminoguanidine (AMG). The early phase after Tx might be considered as a critical step in the rejection process and blockade of early cell infiltration might prevent or attenuate rejection (Michel et al. 2006, Healy et al. 2006).

\section{Methods}

\section{Animals}

Mice of inbred strains, which differ in major and minor histocompatibility antigens, were used. Female mice of C57BL/10 (B10; H-2 ${ }^{\mathrm{b}}$ ) strain (Velaz, Lysolaje) served as corneal graft donors. Male and female mice of BALB/c $\left(\mathrm{H}-2^{\mathrm{d}}\right)$ strain (Institute of Molecular Genetics, Prague), 6-8 weeks old, were used as recipients. Approximately 200 mice were used in this study. Animals were kept under conventional conditions and were acclimatized in our facility for a minimum of 7 days prior to experimentation. They had free access to water and commercial pelleted food. All procedures were performed in accordance with the general guidelines of the First Faculty of Medicine, Charles University in Prague.

\section{Operative technique and treatments}

Orthotopic allogeneic corneal $\mathrm{Tx}$ in mice was performed (C57BL/10 to BALB/c). Briefly, donor corneas $2 \mathrm{~mm}$ in diameter were excised and placed in balanced salt solution. Instilling viscoelastic material (Provisc, Alcon) into the anterior chamber during the explantation protected the donor endothelium. The recipients were anesthetized by intramuscular injection of $1.5 \mathrm{mg}$ ketamine (Narkamon $5 \%$, Spofa Prague) and $0.3 \mathrm{mg}$ xylazine (Rometar $2 \%$, Spofa Prague). To dilate the pupil, a combination of tropicamide $1 \%$ (Mydrum, Chauvin Ankerpharm GmbH, Germany) and phenylephrine $10 \%$ (Neo-Synephrine, Abbott Laboratories, Chicago, USA) drops was used. The recipient cornea was outlined with trephine (1.5 $\mathrm{mm}$ in diameter) and excised using Vannas scissors after penetrating the anterior chamber with a sharp needle. Donor graft was placed on the recipient bed covered with viscoelastic material and sutured with running suture (Ethilon 11/0, $50 \mu \mathrm{m}$ diameter needle, Ethicon). Provisc was used to maintain the anterior chamber throughout the procedure. Neomycin and bacitracin ointment was applied into the conjunctival sac after the operation (Framykoin ophth., Zentiva, Prague). The suture was not removed.

Therapy included FK506 $(0.2 \mathrm{mg} / \mathrm{kg}$ applied in the volume of $200 \mu \mathrm{l}), \mathrm{MM}(30 \mathrm{mg} / \mathrm{kg}$ applied in the volume of $100 \mu \mathrm{l})$ or AMG $(0.1 \mathrm{~g} / \mathrm{kg}$ applied in the volume of $200 \mu \mathrm{l}$ ), started at the day of Tx and was injected intraperitoneally daily. Saline in the volume of $200 \mu \mathrm{l}$ was administered to control group. Corneas were excised on the third and seventh day after Tx. 


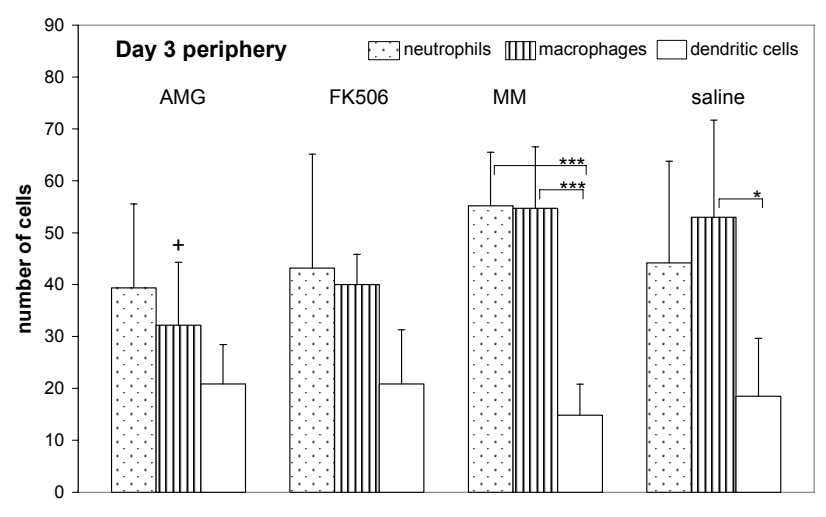

Fig. 1. The effect of AMG, FK506, MM and saline on NPHs, MPHs and DC infiltration in the periphery of corneal graft, the 3rd day after transplantation. Results are expressed as means \pm SD. Statistical analysis was performed using one-way ANOVA test or Mann-Whitney test: * $p<0.05,{ }^{* * *} p<0.0001,+p<0.05$ vs. the same type of cells in saline control group.

\section{Evaluation}

The grafts were examined every other day through the operating microscope (Leica) and evaluated according to the grade of opacity 0-4 (Plšková et al. 2004). Mice with complications such as cataract, infection or hemorrhage were excluded from the study (approximately $15 \%$ of the total number of animals).

\section{Reagents and antibodies}

Chemicals and reagents for immunohistochemistry (Gelatin, Nonodet, EDTA) were purchased from Sigma (Germany). Antibodies: Monos/Macros monoclonal antibody (MoMa) (Serotec, UK), NIMP (HyCult biotechnology, Netherlands), CD11c hamster anti-mouse (Serotec, UK), rat IgG2b (Serotec, UK), TRITC donkey anti-rat (Jackson ImmunoResearch, USA), TRITC goat anti-hamster (Jackson ImmunoResearch, USA) and Fc block (Serotec, UK).

\section{Immunostaining of corneal tissue}

Immunostaining of corneal tissue was performed as described previously (Brisette-Storkus et al. 2002, Danjo et al. 1987). Briefly, mice were killed by cervical dislocation on the third and seventh day after Tx and the corneas were excised. The corneal stroma and epithelium were then separated after 30 -min incubation at $37^{\circ} \mathrm{C}$ in $20 \mathrm{mM}$ EDTA. After separation, the corneal stromas were fixed for $30 \mathrm{~min}$ at $4{ }^{\circ} \mathrm{C}$ in $1 \%$ paraformaldehydePBS followed by extensive washing in PBS. After the washing step, corneal tissue was incubated overnight at $4{ }^{\circ} \mathrm{C}$ with primary antibody (MoMa) diluted in PBS-
BGEN (PBS containing $3 \%$ BSA, $0.25 \%$ Gelatin, $5 \mathrm{mM}$ EDTA, $0.025 \%$ Nonodet). The tissue was then washed 5 times $10 \mathrm{~min}$ each in PBS. Tissues stained with fluorescently labelled secondary antibody $\left(6 \mathrm{~h}\right.$ in $\left.4{ }^{\circ} \mathrm{C}\right)$ were then washed extensively, fixed again with $1 \%$ paraformaldehyde-PBS for $30 \mathrm{~min}$ and placed on slides, mounted with mounting medium (Permafluor, Immunotech) and coverslipped.

When using other antibodies (NIMP), it was not necessary to separate the epithelium.

For visualization of CD11c staining, the blocking step was crucial. After fixation, the corneal tissue was blocked for $40 \mathrm{~min}$ at $4{ }^{\circ} \mathrm{C}$ with Fc-Block and then incubated overnight with primary antibody. The method was continued as described above.

\section{Enumeration of cells}

Each cornea was divided into five sections, three from the area of suture (periphery) and two from the center of the cornea. The area round the knot was omitted because it does not represent conditions in the whole cornea. The image was taken by fluorescent microscopy (Olympus AX70) from each of these predefined sections and specific square $400 \times 400$ pixels $(265 \times 265 \mu \mathrm{m})$ has been removed randomly. In any case the areas were not overlaid. Using the accompanying software (Analysis Pro 5.0) the positive cells were enumerated manually. For each time point (day 3 and 7 after Tx), each therapy (AMG, FK506, MM, saline) and each staining (MoMa, NIMP, CD11c) at least 3 corneas were used and controls in addition (rat IgG2b, PBS - negative control).

\section{Statistical analysis}

Statistical analysis was performed using oneway ANOVA test or Mann-Whitney test using GraphPad InStat software.

\section{Results}

Figures 1 and 2 demonstrate the effect of $\mathrm{AMG}$, FK506, MM and saline on NPHs, MPHs and DC infiltration in the periphery and in the center of corneal graft on the third day after Tx. There was an increase in number of infiltrating leukocytes, in particular MPHs and NPHs and significantly lesser extent of DC in the periphery of corneal allograft.

Under the AMG therapy there are no significant differences among the numbers of cells. The amount of NPHs is similar in the periphery and in the center of 


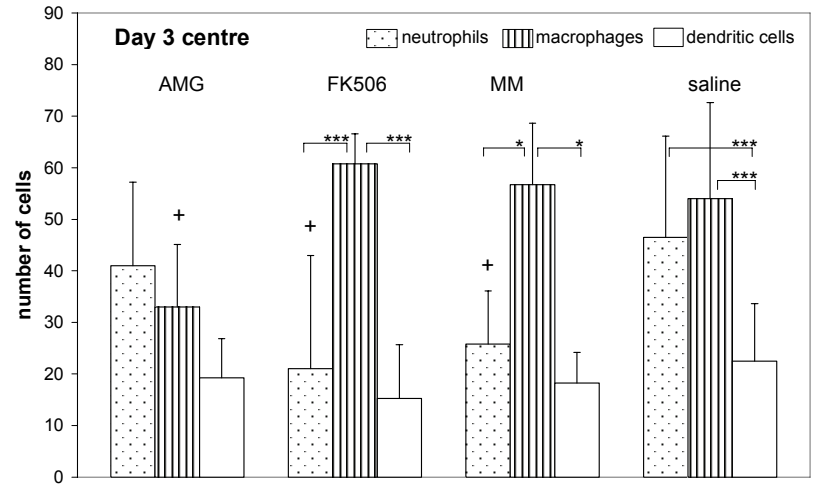

Fig. 2. The effect of AMG, FK506, MM and saline on NPHs, MPHs and DC infiltration in the center of corneal graft, the 3rd day after transplantation. Results are expressed as means \pm SD. Statistical analysis was performed using one-way ANOVA test or MannWhitney test: * $p<0.05,{ }^{* * *} p<0.0001,+p<0.05$ vs. the same type of cells in saline control group.

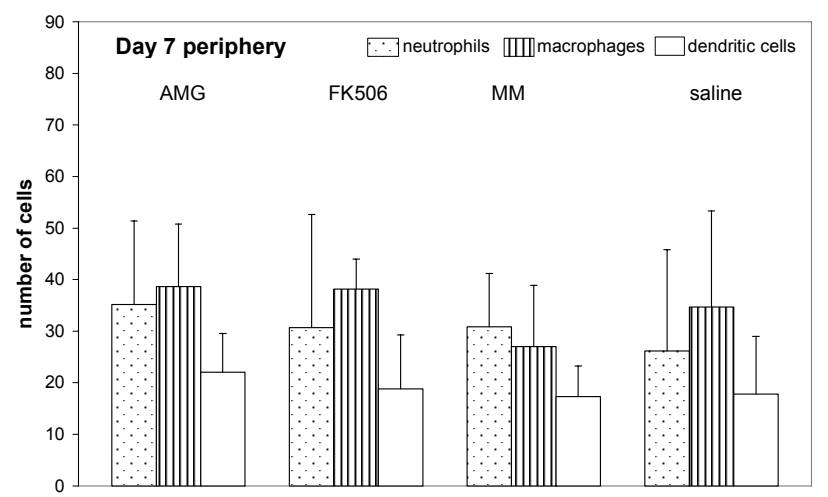

Fig. 3. The effect of AMG, FK506, MM and saline on NPHs, MPHs and $\mathrm{DC}$ infiltration in the periphery of corneal graft, the 7th day after transplantation. Results are expressed as means \pm SD. Statistical analysis was performed using one-way ANOVA test or Mann-Whitney test.

graft. These results are consistent with the number of MPHs in the center and in the periphery of corneal allograft in this early phase after $\mathrm{Tx}$.

Therapy with FK506 decreases the number of NPHs $(p<0.001)$ and DC $(p<0.001)$ in the center of the graft compared with the quantity of MPHs. In the periphery of the graft the incidence of NPHs and MPHs is higher than the number of DC, but the difference is not statistically significant.

The MM therapy significantly reduces the number of DC in the periphery of the graft comparing with MPHs ( $\mathrm{p}<0.001)$ or NPHs ( $\mathrm{p}<0.001)$, whose number is similarly high. In the center of allograft, under the MM therapy, there is significantly lesser number of DC $(\mathrm{p}<0.05)$ and NPHs $(\mathrm{p}<0.05)$ in comparison with the amount of MPHs.

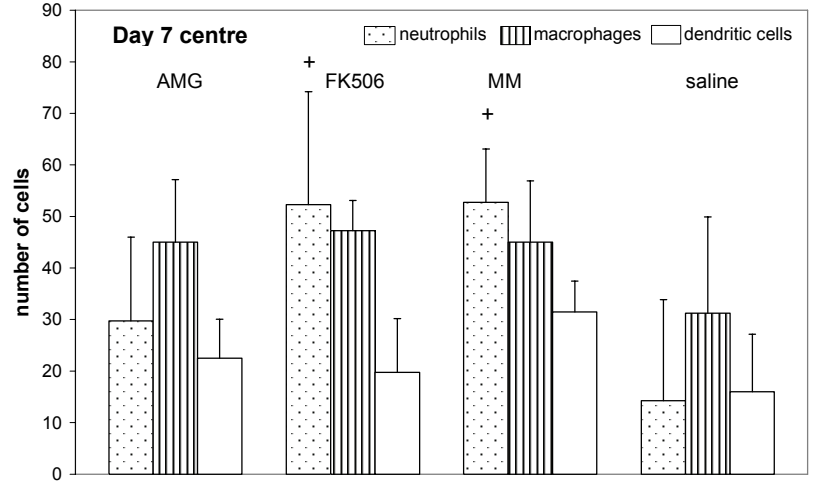

Fig. 4. The effect of AMG, FK506, MM and saline on NPHs, MPHs and $D C$ infiltration in the center of corneal graft, the 7th day after transplantation. Results are expressed as means \pm SD. Statistical analysis was performed using one-way ANOVA test or MannWhitney test: $+p<0.05$ vs. the same type of cells in saline control group.

The quantity of MPHs and NPHs is also high in the periphery of the graft treated with saline, but only the number of MPHs is significantly greater $(p<0.05)$ than the quantum of DC. This situation is similar in the center of allograft, the number of MPHs $(\mathrm{p}<0.001)$ or NPHs $(p<0.001)$ is significantly higher than the amount of DC.

Figures 3 and 4 demonstrate the effect of AMG, FK506, MM and saline on NPHs, MPHs and DC infiltration in the periphery and in the center of corneal graft, on the 7th day after Tx. Grafts are strongly infiltrated by MPHs and NPHs, while the number of DC is lower. There are more cells in the center of the allografts than in the periphery, but these differences are not statistically significant.

The number of NPHs is similar in all four groups treated by AMG, FK506, MM or saline in the periphery of the grafts. In the center, the numbers of NPHs slightly differ but without significance. We found the highest number of NPHs in grafts under the therapy of FK506 and MM, while the lowest number of NPHs was found in control group treated by saline. The only significant difference between the peripheral and the central part of the graft was seen under the saline, where the number of NPHs in the periphery was significantly higher than in the center $(p=0.0328)$.

The levels of DC remain similar in the peripheries of the grafts. There are differences in the center, where the number of DC is highest in grafts under the MM therapy and the lowest in control grafts.

Generally, the number of DC in the periphery has descendent trend between third and seventh day after the Tx, except the MM therapy. Growing trend can be 
seen when we observe DC in the center of the graft between third and seventh day after the Tx, except the control group.

When we focus on NPHs in the periphery of the allografts from third to seventh day after Tx, their number in all treated groups exhibits decreasing trend. In the center, two different phenomena can be seen. AMG therapy and saline showed downward tendency between day 3 and 7, whereas MM and FK506 therapy showed growing trend.

MPHs in the center of the allografts between day 3 and 7 after Tx have downward tendency, except MPHs in grafts treated with AMG, whose level on day 7 is higher than day 3 after Tx. The same trend can be seen in the periphery.

Compared with control, treatment with FK506 or MM led to a significant decrease $(p<0.05)$ of NPHs on day 3 after Tx and their significant increase $(p<0.05)$ on the day 7 after Tx in the center of corneal allografts. In contrast, AMG reduced significantly $(\mathrm{p}<0.05)$ MPHs migration into allografts, both in the center and in the periphery, on the 3rd day after Tx, whereas NPHs infiltration has not been attenuated.

\section{Discussion}

The aim of this study was to delineate the infiltration of non-specific immunity cells (MPHs, NPHs, DC) into corneal allograft in the early phases after Tx. Immunohistochemical techniques were employed to quantify these cells on day 3 and day 7 after corneal Tx.

Corticosteroids, non-steroid immunosuppressive agents, and improved surgical techniques (Plšková et al. 2002) have allowed us to improve allograft surgical rates; however, lack of understanding about the process of corneal allograft rejection limits our ability to prevent immunologically mediated corneal graft failure (Hargrave et al. 2003). The immunohistological studies showed a massive infiltration of rejected corneal allografts by MPHs and CD4+ lymphocytes. CD8+ lymphocytes, activated by CD4+ T-cells, have been considered for a long time to be the main effector cells in the rejection process. Further studies brought evidence that activated MPHs are the key cytotoxic cell population in process of skin allograft rejection in mice (Yamamoto et al. 1998). It is known that prevention of early allograft NPHs saturation may prevent tissue damage and attenuate lymphocyte activity (Healy et al. 2006). That is why we tried to estimate the effect of immunosuppressants on the kinetics of non-specific immunity cells in the early phases after Tx. We also presume that the center of the corneal graft has different characteristics in comparison with the periphery. For this reason we tried to evaluate these two compartments separately.

Although the normal cornea does not contain vessels, there is indirect immunohistochemical evidence that it is endowed with a significant number of resident bone-marrow (BM) derived cells (Nakamura et al. 2005, Yamagami et al. 2006). It was reported that corneal stroma contains significant number of resident DC (Hamrah et al. 2003b) and Langerhans cells (form of DC) in murine corneal epithelium (Hamrah et al. 2002). More recently, it was shown that BM-derived cells also reside in normal non-inflamed stroma (Brisette-Storkus et al. 2002, Yamagami et al. 2003).

The infiltration of allografted murine corneas with inflammatory cells starts immediately after the initial surgery. The first cells infiltrating the graft seemed to be myeloid cells, both mononuclear and polymorphonuclear. The migration of all types of cells was initiated within $24 \mathrm{~h}$ after grafting and was sustained for many weeks only declining in number after the graft was accepted or rejected (Kuffová et al. 2001).

In the early phases after $\mathrm{Tx}$, a massive infiltration of MPHs and NPHs into corneal grafts was revealed, in accordance with other studies (Holán et al. 2001, Kuffová et al. 2001, Larkin et al. 1997a, Novak et al. 2003, Yamagami et al. 2003, Oshima et al, 2006, Svozílková et al. 2006). The amount of DC was significantly lower and there were no difference between day 3 and 7 after Tx. FK506 and the antiproliferative MM exert only a minor influence on dendritic cell differentiation, maturation or migration, although both agents suppress DC allo-co-stimulatory capacity by decreasing TNF- $\alpha$ and IL-12 secretion, respectively (Athanassopoulos et al. 2005). It is known that immature resident myeloid DC in the corneal stroma mature as a result of corneal inflammation (Hamrah et al. 2003a, Novak et al. 2003), dramatic boost of DC would be observed during the rejection. On the basis of our data, we suggest that immunosuppressants had no influence on number of infiltrating DC during early phases after Tx.

The present results have revealed that control groups have approximately similar characteristics (relating to the number of non-specific immunity cells) on day 3 or 7 after Tx, in the centers or in the peripheries. The most frequently represented cells are NPHs and MPHs in control group. Number of these cells is higher 
in the peripheries than centers and their count has downward tendency from day 3 to 7 after Tx both, in the centers and peripheriesell. We tried to estimate the efficiency of the treatments (FK506, MM, and AMG) compared to saline therapy.

Based on our results, FK506 and MM do not influence the number of MPHs on the 3 rd or 7 th day after Tx, either in the corneal graft center or in the periphery. In addition, there are no changes in the number of NPHs on day 3 or 7 after Tx in the periphery compared with control group. On the contrary, there can be found reduction of NPHs on the day 3 after Tx and augmentation of NPHs on the day 7 after Tx, both in the center of the grafts. It is known, that NPHs are one of the first leukocytes to infiltrate allograft with the peak during the first day after Tx but clearing by $72 \mathrm{~h}$ (Healy et al. 2006). Our data indicated that immunosuppressants FK506 and MM delay this peak from day 3 after Tx further.

AMG significantly reduced MPH migration into allografts, both in the center and to the periphery on day 3 after Tx, whereas MPHs migration on day 7 after Tx or NPHs infiltration have not been attenuated or increased significantly. AMG is an inhibitor of inducible nitric oxide synthase, but its biologic effect may not exclusively depend on the inhibition of nitric oxide synthase and may, by other means, reduce proinflammatory cytokines, which are involved especially in the early phase after Tx (Kim et al. 2003).

In conclusion, we suggest that corneal grafts in the center and in the periphery might be infiltrated by non-specific immunity cells differently. AMG has an inhibitory effect on MPHs, whereas FK506 and MM influence the number of NPHs in comparison with saline. DC seems to be inert to the influence of immunosuppressants in the early phases after Tx. The exact effect of immunosuppressive agents on non-specific immunity cells, however, remains unclear and needs further investigation.

\section{Acknowledgements}

This study was supported by Grants GAČR 305/03/D130 and VZ MSM 0021620807. FK506 was kindly supplied by Fujisawa GmBH (Munich, Germany) and MM by Roche (Czech Republic). Our thanks are due to Prof. Ivan Raška for giving us the possibility for using the confocal and fluorescent microscopy and to Prof. Jindřich Martínek for his valuable help. We thank Ms. Jana Bucková for her skillful technical assistance.

\section{References}

ATHANASSOPOULOS P, VAESSEN LM, MAAT AP, ZONDERVAN PE, BALK AH, BOGERS AJ, WEIMAR W: Preferential depletion of blood myeloid DC during acute cardiac allograft rejection under controlled immunosuppression. Am J Transplant 5: 810-820, 2005.

BRADLEY BA: Rejection and recipient age. Transpl Immunol 10: 125-132, 2002.

BRISSETTE-STORKUS CS, REYNOLDS SM, LEPISTO AJ, HENDRICKS RL: Identification of a novel macrophage population in the normal mouse corneal stroma. Invest Ophthalmol Vis Sci 43: 2264-2271, 2002.

DANA MR, QIAN Y, HAMRAH P: Twenty-five-year panorama of corneal immunology: emerging concepts in the immunopathogenesis of microbial keratitis, peripheral ulcerative keratitis, and corneal transplant rejection. Cornea 19: 625-643, 2000.

DANJO S, FRIEND J, THOFT R: Conjunctival epithelium in healing of corneal epithelial wounds. Invest Ophthalmol Vis Sci 28: 1445-1449, 1987.

HAMRAH P, ZHANG Q, LIU Y, DANA MR: Novel characterization of MHC class II-negative population of resident corneal langerhans cell-type DC. Invest Ophthalmol Vis Sci 43: 639-646, 2002.

HAMRAH P, LIU Y, ZHANG Q, DANA MR: Alterations in corneal stromal dendritic cell phenotype and distribution in inflammation. Arch Ophthalmol 121: 1132-1140, 2003a.

HAMRAH P, LIU Y, ZHANG Q, DANA MR: The corneal stroma is endowed with a significant number of resident dendritic cells. Invest Ophthalmol Vis Sci 44: 581-589, $2003 \mathrm{~b}$.

HARGRAVE SL, MAYHEW E, HEGDE S, NIEDERKORN J: Are corneal cells susceptible to antibody-mediated killing in corneal allograft rejection? Transpl Immunol 11: 79-89, 2003. 
HEALY DG, WATSON RW, O'KEANE C, EGAN JJ, MCCARTHY JF, HURLEY J, FITZPATRICK J, WOOD AE: Neutrophil transendothelial migration potential predicts rejection severity in human cardiac transplantation. Eur J Cardiothorac Surg 29: 760-766, 2006.

HEGDE S, BEAUREGARD C, MAYHEW E, NIEDERKORN J: CD4+ T-cell-mediated mechanisms of corneal allograft rejection: role of Fas-induced apoptosis. Transplantation 79: 23-31, 2005.

HOLÁŇ V, KRULOVÁ M, PINDJÁKOVÁ J, ZAJÍCOVÁ A: The role of macrophages and nitric oxide in the effector phase of allotransplantation reaction. Ann Transplant 6: 44-46, 2001.

KIM JY, KIM D, LEE EM, CHOI I, PARK CG, KIM KS, HA J, KIM SJ, YANG J, KIM YS, HAN JS, KIM S, LEE JS, AHN C: Inducible nitric oxide synthase inhibitors prolonged the survival of skin graft xenografts through selective down-regulation of pro-inflammatory cytokine and CC-chemokine expressions. Transpl Immunol 12: 63-72, 2003.

KUFFOVÁ L, LUMSDEN L, VESELÁ V, TAYLOR JA, FILIPEC M, HOLAN V, DICK AD, FORRESTER JV: Kinetics of leukocyte and myeloid cell traffic in the murine corneal allograft response. Transplantation $\mathbf{7 2 :}$ 1292-1298, 2001.

LARKIN DF, ALEXANDER RA, CREE IA: Infiltrating inflammatory cell phenotypes and apoptosis in rejected human corneal allografts. Eye 11: 68-74, 1997a.

LARKIN DF, CALDER VL, LIGHTMAN SL: Identification and characterization of cells infiltrating the graft and aqueous humour in rat corneal allograft rejection. Clin Exp Immunol 107: 381-391, 1997b.

MARUYAMA K, II M, CURSIEFEN C, JACKSON DG, KEINO H, TOMITA M, VAN ROOIJEN N, TAKENAKA H, D'AMORE PA, STEIN-STREILEIN J, LOSORDO DW, STREILEIN JW: Inflammation-induced lymphangiogenesis in the cornea arises from CD11b-positive macrophages. J Clin Invest 115: 2363-2372, 2005.

MICHEL DC, NERRIERE-DAQUIN V, JOSIEN R, BRACHET P, NAVEILHAN P, NEVEU I: Dendritic cell recruitment following xenografting of pig fetal mesencephalic cells into the rat brain. Exp Neurol 202: 76-84, 2006.

NAKAMURA T, ISHIKAWA F, SONODA K, HISATOMI T, QIAO H, YAMADA J, FUKATA M, ISHIBASHI T, HARADA M, KINOSHITA S: Characterization and distribution of bone marrow-derived cells in mouse cornea. Invest Ophthalmol Vis Sci 46: 497-503, 2005.

NOVAK N, SIEPMANN K, ZIERHUT M, BIEBER T: The good, the bad and the ugly APCs of the eye. Trends Immunol 24: 570-574, 2003.

OSHIMA T, SONODA K, TSUTSUMI-MIYAHARA C, QIAO H, HISATOMI T, NAKAO S, HAMANO S, EGASHIRA K, CHARO IF, ISHIBASHI T: Analysis of corneal inflammation induced by cauterisation in CCR2 and MCP-1 knockout mice. Br J Ophthalmol 90: 218-222, 2006.

PLŠKOVÁ J, KUFFOVÁ L, HOLÁŇ V, FILIPEC M, FORRESTER JV: Evaluation of corneal graft rejection in a mouse model. Br J Ophthalmol 86: 108-113, 2002.

PLŠKOVÁ J, KUFFOVÁ L, FILIPEC M, HOLÁŇ V, FORRESTER JV: Quantitative evaluation of the corneal endothelium in the mouse after grafting. Br J Ophthalmol 88: 1209-1216, 2004.

QIAN Y, DANA MR: Molecular mechanisms of immunity in corneal allotransplantation and xenotransplantation. Expert Rev Mol Med 16: 1-21, 2001.

SVOZÍLKOVÁ P, BYSTERSKÁ P, MAŠEK K, VALENTA Z, ZVÁROVÁ J, FARGHALI H: Comparison of FK506, mycophenolate mofetil and aminoguanidine effects on delay of corneal allograft rejection in an experimental model of low-risk and high-risk keratoplasty. Immunopharmacol Immunotoxicol 28: 335-340, 2006.

TORRES PF, DE VOS AF, VAN DER GAAG R, MARTINS B, KIJLSTRA A: Cytokine mRNA expression during experimental corneal allograft rejection. Exp Eye Res 63: 453-461, 1996.

YAMAGAMI S, AMANO S: Role of resident corneal leukocytes and draining cervical lymph nodes in corneal allograft rejection. Cornea 22 (Suppl): S61-S65, 2003.

YAMAGAMI S, EBIHARA N, USUI T, YOKOO S, AMANO S: Bone marrow-derived cells in normal human corneal stroma. Arch Ophthalmol 124: 62-69, 2006. 
YAMAMOTO N, EINAGA-NAITO K, KURIYAMA M, KAWADA Y, YOSHIDA R: Cellular basis of skin allograft rejection in mice: specific lysis of allogeneic skin components by non T-cells. Transplantation 65: 818-825, 1998.

\section{Corresponding author}

Petra Svozílková, Department of Ophthalmology, First Faculty of Medicine, Charles University, U Nemocnice 2, 12808 Prague 2, Czech Republic. E-mail: psvoz@1f1.cuni.cz 